\title{
A study of genes encoding cytokines (IL6, IL10, TNF), cytokine receptors (IL6R, IL6ST), and glucocorticoid receptor (NR3C1) and susceptibility to bronchopulmonary dysplasia
}

Johanna M Huusko ${ }^{1,2^{*}}$, Minna K Karjalainen ${ }^{1,2}$, Mari Mahlman ${ }^{1,2}$, Ritva Haataja ${ }^{1,3}$, M Anneli Kari $^{4}$, Sture Andersson ${ }^{4}$, Gergely Toldi ${ }^{5}$, Outi Tammela ${ }^{6}$, Mika Rämet ${ }^{1,2,6,7}$, Pascal M Lavoie ${ }^{8}$, and Mikko Hallman ${ }^{1,2}$ on behalf of Gen-BPD Study Group

\begin{abstract}
Background: Bronchopulmonary dysplasia (BPD) is a common chronic lung disease associated with very preterm birth. The major risk factors include lung inflammation and lung immaturity. In addition, genetic factors play an important role in susceptibility to moderate-to-severe BPD. In this study, the aim was to investigate whether common polymorphisms of specific genes that are involved in inflammation or differentiation of the lung have influence on BPD susceptibility.

Methods: Genes encoding interleukin-6 (IL6) and its receptors (IL6R and IL6ST), IL-10 (IL 10), tumor necrosis factor (TNF), and glucocorticoid receptor (NR3C1) were assessed for associations with moderate-to-severe BPD susceptibility. Five $I L 6$, nine $I L 6 R$, four $I L 6 S T$, one $I L 10$, two $T N F$, and $23 N R 3 C 1$ single nucleotide polymorphisms (SNPs) were analyzed in very preterm infants born in northern Finland (56 cases and 197 controls) and Canada (58 cases and 68 controls). IL-6, TNF and gp130 contents in umbilical cord blood, collected from very preterm infants, were studied for associations with the polymorphisms. Epistasis (i.e., interactions between SNPs in BPD susceptibility) was also examined. SNPs showing suggestive associations were analyzed in additional replication populations from Finland (39 cases and 188 controls) and Hungary (29 cases and 40 controls).

Results: None of the studied SNPs were associated with BPD nor were the IL6, TNF or IL6ST SNPs associated with cord blood IL-6, TNF and gp130, respectively. However, epistasis analysis suggested that SNPs in IL6ST and IL10 were associated interactively with risk of BPD in the northern Finnish population; however, this finding did not remain significant after correction for multiple testing and the finding was not replicated in the other populations.
\end{abstract}

Conclusions: We conclude that the analyzed SNPs within IL6, IL6R, IL6ST, IL10, TNF, and NR3C1 were not associated with BPD. Furthermore, there was no evidence that the studied SNPs directly contribute to the cord blood protein contents.

Keywords: Bronchopulmonary dysplasia, Epistasis, Glucocorticoid receptor, Interleukin, Preterm infant, Single nucleotide polymorphism

\footnotetext{
* Correspondence: johanna.huusko@oulu.fi

${ }^{1}$ Department of Pediatrics, Institute of Clinical Medicine, Medical Research

Center Oulu, Oulu University Hospital and University of Oulu, Oulu, Finland

${ }^{2}$ Department of Children and Adolescents, Oulu University Hospital, Oulu,

Finland

Full list of author information is available at the end of the article
} 


\section{Background}

Bronchopulmonary dysplasia (BPD) is a chronic lung disease that affects infants born very preterm. Despite advances in treatment practices (including antenatal glucocorticoid treatment), BPD continues to be a major cause of neonatal morbidity and mortality in these infants. Furthermore, infants with BPD are at increased risk of respiratory morbidities in later life, and lung function defects may persist even into adulthood [1]. Major risk factors that predispose infants to BPD include prematurity [2], fetal growth restriction [3], and lung inflammation [4]. In addition to environmental stressors, the results of twin studies indicate high heritability for BPD and that the genetic factors have an important role in predisposition to BPD [5-7] accounting for up to $79 \%$ of the variance in liability to moderate-to-severe BPD [6]. Despite numerous candidate gene studies and two genome-wide association studies, the genetic background of BPD remains incompletely characterized [8-11].

Infants with BPD often have a simplified lung structure. It has been proposed that initiation of an inflammatory cascade in immature lung tissue interferes with the normal course of septation and alveolar development. This leads to fewer, simplified, and larger alveoli and dysmorphic pulmonary vasculature, which are typical features of impaired alveolarization and common findings in BPD $[4,12]$. In addition, the inflammatory cytokines are strongly associated with the airway and interstitial lung injury, and thus, several inflammatory mediators have been studied for associations with BPD [13]. Previously, elevated levels of cytokines were observed in blood, cord blood or amniotic fluid from infants who subsequently developed BPD [14-16]. In particular, elevated levels of proinflammatory cytokine interleukin 6 (IL-6) in blood after birth [14], glycoprotein 130 (gp130, also known as IL-6 signal transducer) in cord blood [15] and reduced expression of IL-10 in placenta [17] were associated with risk of BPD.

This case-control study was performed to assess whether genes involved in inflammation and lung maturation are associated with susceptibility to moderate-to-severe BPD, defined by the need of supplemental oxygen at the corrected age of 36 weeks. The genes encoding IL-6 (IL6), its receptors IL-6R (IL6R) and gp130 (IL6ST), IL-10 (IL10), tumor necrosis factor (TNF) formerly known as TNF-alpha, were studied. In addition, the gene encoding glucocorticoid receptor (NR3C1) was selected. Glucocorticoids have strong anti-inflammatory effects, and they additionally influence growth and differentiation. The actions of both endogenous and synthetic glucocorticoids are mediated by the glucocorticoid receptor $[18,19]$. Furthermore, associations between specific polymorphisms and cord blood serum IL-6, TNF and gp130 contents were studied. Finally, epistasis was investigated; i.e., whether interactions between polymorphisms in the six analyzed genes affect disease susceptibility.

\section{Methods}

Written informed consent was obtained from the parents, and the study was approved by the Ethics Committee of Oulu University Hospital, the University of British Columbia Clinical Research Ethics Board, the University of Alberta Ethics Board, and the Semmelweis University Hospital Ethical Committee.

\section{Diagnosis of BPD and infant inclusion criteria}

The diagnosis of BPD was based on a requirement for supplemental oxygen or ventilation at $36 \mathrm{wk}$ post menstrual age (PMA). For infants who required supplemental oxygen for a minimum of $28 \mathrm{~d}$, the severity of BPD was graded (according to National Institute of Child Health and Human Development criteria) as mild BPD (no supplemental $\mathrm{O}_{2}$ requirement or ventilation at 36 wk PMA), moderate BPD (supplemental $\mathrm{O}_{2}$ requirement $<30 \%$ at 36 wk PMA), or severe BPD (supplemental $\mathrm{O}_{2}$ requirement $\geq 30 \%$ or ventilation at 36 wk PMA) [20]. The oxygen reduction test [21] was performed for infants born in Finland after 2009; the test eliminated less than $10 \%$ of all cases of moderate BPD. Although infants from different centers were included in the study, the possible differences in BPD diagnosis were small since the transcutaneous oxygen saturation limits were kept within a close range (lower limit from 86 to $90 \%$; upper limit from 92 to $95 \%$ ), the oxygen saturation test was similar in each center, and of all infants studied only one third of the Canadian population was treated in moderately high altitude $(\sim 670 \mathrm{~m})$.

In case-control analyses, infants with no-to-mild BPD were controls and infants with moderate-to-severe BPD were cases. This approach was based on twin studies that demonstrated significant heritability in moderateto-severe BPD but less in mild BPD [6]. We excluded infants with malformations and those who died before the diagnosis. Additionally, only one infant was included from each monozygotic twin pair.

\section{Study populations}

All infants were born at gestational age $(\mathrm{GA})<31$ wk. Clinical characteristics are presented in Table 1. The northern Finnish population ( $\mathrm{n}=253$ ) was prospectively recruited at Oulu University Hospital in 1997-2010. Only infants with parents of Finnish origin were included. The study population that originated Canada $(\mathrm{n}=126)$ comprised infants born in neonatal intensive care units in Vancouver and Edmonton in 2006-2008, as described previously [22]. These infants were of European descent. In addition, two replication populations were included. The first population comprised infants born in Finland $(\mathrm{n}=227)$ in the university hospitals of Oulu, Kuopio, Tampere, and Helsinki in 2010-2012 and in the University Hospital of Turku in 2001-2006 and 
Table 1 Clinical characteristics of the northern Finnish, Canadian, replication Finnish, and replication Hungarian preterm cohorts

\begin{tabular}{|c|c|c|c|c|c|c|c|c|}
\hline \multirow[b]{3}{*}{$\underline{\mathbf{n}}$} & \multicolumn{2}{|c|}{ Northern Finnish } & \multicolumn{2}{|l|}{ Canadian } & \multicolumn{2}{|c|}{ Replication Finnish } & \multicolumn{2}{|c|}{ Replication Hungarian } \\
\hline & BPD cases & Controls & BPD cases & Controls & BPD cases & Controls & BPD cases & Controls \\
\hline & 56 & 197 & 58 & 68 & 39 & 188 & 29 & 40 \\
\hline $\begin{array}{l}\text { Gestational age, } \\
\text { weeks }^{1}\end{array}$ & $\begin{array}{l}27.5 \pm 1.9 \\
(24-30)\end{array}$ & $\begin{array}{l}28.7 \pm 1.7 \\
(23-30)^{* * *}\end{array}$ & $\begin{array}{l}25.9 \pm 1.6 \\
(23-30)\end{array}$ & $\begin{array}{l}27.6 \pm 1.3 \\
(24-30)^{* * *}\end{array}$ & $\begin{array}{l}26.5 \pm 1.9 \\
(24-30)\end{array}$ & $\begin{array}{l}27.5 \pm 2.0 \\
(23-30)^{* *}\end{array}$ & $\begin{array}{l}26.6 \pm 1.8 \\
(24-30)\end{array}$ & $\begin{array}{l}28.6 \pm 1.4 x \\
24-30)^{* * * *}\end{array}$ \\
\hline $\begin{array}{l}\text { Gestational age <28 } \\
\text { wk, n (\%) }\end{array}$ & $29(51.8)$ & $64(32.5)^{* *}$ & $48(82.8)$ & $32(47.1)^{* * *}$ & $30(76.9)$ & $88(46.8)^{* *}$ & $19(65.5)$ & $6(15.0)^{* * *}$ \\
\hline Birth weight, grams ${ }^{1}$ & $\begin{array}{l}938 \pm 268 \\
(495-1555)\end{array}$ & $\begin{array}{l}1184 \pm 313 \\
(370-1850)^{* * *}\end{array}$ & $\begin{array}{l}834 \pm 221 \\
(385-1420)\end{array}$ & $\begin{array}{l}1162 \pm 243 \\
(630-1900)^{* * *}\end{array}$ & $\begin{array}{l}878 \pm 257 \\
(440-1470)\end{array}$ & $\begin{array}{l}1074 \pm 308 \\
(520-1970)^{* * *}\end{array}$ & $\begin{array}{l}928 \pm 226 \\
(510-1500)\end{array}$ & $\begin{array}{l}1179 \pm 193 \\
(650-1500)^{* * *}\end{array}$ \\
\hline Birth weight $Z$-score $e^{1,2}$ & $\begin{array}{l}-1.4 \pm 1.41 \\
(-4.5-1.8)\end{array}$ & $\begin{array}{l}-0.9 \pm 1.22 \\
(-5.5-1.7)^{*}\end{array}$ & NA & NA & $\begin{array}{l}-1.4 \pm 1.38 \\
(-4.0-1.1)\end{array}$ & $\begin{array}{l}-0.9 \pm 1.3 \\
(-4.0-2.6)\end{array}$ & NA & NA \\
\hline$I U G R \leq-2 S D, n(\%)$ & $21(37.5)$ & $33(16.8)^{* *}$ & $11(19.0)$ & $3(4.4)^{*}$ & $13(33.3)$ & $41(21.8)$ & NA & NA \\
\hline Male gender, n (\%) & $34(60.7)$ & $111(56.3)$ & $29(50.0)$ & $30(44.1)$ & $26(66.7)$ & $94(50.0)$ & $16(55.2)$ & $24(60.0)$ \\
\hline Singletons, n (\%) & $47(83.9)$ & $164(83.2)$ & $39(67.2)$ & $44(64.7)$ & $29(74.4)$ & $138(73.4)$ & $26(89.7)$ & $33(82.5)$ \\
\hline Severe BPD, n (\%) & $21(37.5)$ & & $21(36.2)$ & & $18(46.2)$ & & NA & \\
\hline
\end{tabular}

${ }^{*} P<0.05$, ${ }^{*} P<0.01,{ }^{* * *} P<0.001$; Mann-Whitney $U$-test for continuous variables, $X^{2}$-test for dichotomous variables; ${ }^{1}$ mean \pm standard deviation (range); ${ }^{2}$ Birth weight $Z$-score describing fetal intrauterine growth. BPD cases were infants with moderate-to-severe BPD, and controls were infants with no-to-mild BPD. BPD, bronchopulmonary dysplasia; IUGR, intrauterine growth restriction; NA, information not available.

2011-2012. This population was not included in the original analyses because samples were prospectively collected during or after the original analyses. The second replication population $(n=69)$ included infants of European descent born in Semmelweis University Hospital, Budapest, Hungary in 1995-2002.

\section{DNA sample preparation}

For the samples collected in Finland, genomic DNA was extracted from buccal cells, umbilical cord blood, and blood spots dried on paper with Chelex 100 (Bio-Rad, Hercules, CA, USA), UltraClean DNA blood Isolation kit (MO BIO Laboratories Inc., Carlsbad, CA, USA), and MO BIO UltraClean BloodSpin DNA Isolation Kit (MO BIO Laboratories), respectively. For buccal cell and paper blood DNA samples, whole-genome amplification was performed, as described previously [23]. For samples that originated in Canada, genomic DNA was extracted from umbilical cord tissue and cell samples, whole blood specimens, and tracheal aspirate samples with the ChargeSwitch gDNA Mini Tissue Kit (Invitrogen, Carlsbad, CA, USA), QIAamp DNA Blood Midi Kit (Qiagen, Hilden, Germany), and ChargeSwitch gDNA Buccal Cell Kit (Invitrogen), respectively. DNA from the Hungarian samples was extracted from dried whole blood spots with saponin and Chelex-100, as described previously [24].

\section{SNP selection and genotyping}

Tagging SNPs (tSNPs) that capture most of the common genetic variation in the selected regions based on linkage disequilibrium (LD) were selected by using HapMap data (release 24/phases I\&II) [25] for the CEU population $(\mathrm{CEPH}$; Utah residents with ancestry from northern and western Europe). A minor allele frequency (MAF) cut-off value of 0.1 and an $r^{2}$ cut-off value of 0.9 were used for pairwise tagging. A total of 44 SNPs (five SNPs in IL6, nine in IL6R, four in IL6ST, one in IL10, two in $T N F$, and 23 in NR3C1) were selected for genotyping. The analyzed SNPs are listed in Tables 2 and 3.

Genotyping was performed with the Sequenom iPLEX Gold assay. Three SNPs deviated from Hardy-Weinberg equilibrium (HWE): IL6R rs4075015 and rs4453032 in the northern Finnish population and IL6 rs2069840 in the Canadian population. Because these SNPs deviated from HWE in only one of the populations, they were included in analyses. In the replication study, IL6ST rs10471960 and IL10 rs3024493 SNPs were genotyped by PCR-RFLP analysis with primer pairs of $5^{\prime}$-CAGAGTGGCTTAGG GACAGTT-3' (forward) and 5'-ACTCGCAGCATCAC TACCAAT-3' (reverse) for rs10471960 and 5'-GGGTG GCTGCTAGGCATTT-3' (forward) and 5'-GAATAGC CCCCTTGTCCCTTC-3' (reverse) for rs3024493, with restriction enzymes BssSI and BamHI (New England Biolabs, Ipswich, MA, USA), respectively.

\section{Analysis of IL-6, TNF and gp130 in umbilical cord blood specimens}

IL-6, TNF and gp130 protein contents were measured from umbilical cord blood specimens collected from a cohort of very preterm infants born in Oulu University Hospital during 1998-2002, as described previously [15]. A total of 120 infants were included in the analysis: 35 infants subsequently developed moderate-to-severe BPD and 85 infants had no-to-mild BPD. The protocol of the antibody-based microarray has been previously described in detail [26]. The protein content of blood specimens are reported as 
Table 2 IL6, IL6R, IL6ST, IL10, and TNF minor allele frequencies in cases and controls in the northern Finnish and Canadian populations

\begin{tabular}{|c|c|c|c|c|c|}
\hline \multirow[b]{2}{*}{ Gene } & \multirow[b]{2}{*}{ Polymorphism ${ }^{1}$} & \multicolumn{2}{|l|}{ Northern Finland, $\mathrm{n}=\mathbf{2 5 3}$} & \multicolumn{2}{|l|}{ Canada, $n=126$} \\
\hline & & Case, control minor allele frequency & $P$ value & Case, control minor allele frequency & $P$ value \\
\hline IL6 & rs2069827 & $0.286,0.265$ & 0.6603 & $0.129,0.119$ & 0.8126 \\
\hline IL6 & rs1800797 & $0.438,0.454$ & 0.7592 & $0.379,0.388$ & 0.8872 \\
\hline IL6 & rs1800795 & $0.438,0.454$ & 0.7523 & $0.404,0.404$ & 0.9884 \\
\hline IL6 & rs2069832 & $0.427,0.457$ & 0.5814 & $0.397,0.404$ & 0.8990 \\
\hline IL6 & rs2069840 & $0.222,0.237$ & 0.7464 & $0.276,0.243$ & 0.5480 \\
\hline IL6R & rs4845617 & $0.400,0.426$ & 0.6304 & $0.276,0.390$ & 0.0568 \\
\hline$I L 6 R$ & rs1386821 & $0.214,0.203$ & 0.795 & $0.172,0.213$ & 0.4144 \\
\hline$\| \angle 6 R$ & rs4075015 & $0.444,0.423$ & 0.6859 & $0.509,0.462$ & 0.4614 \\
\hline$I L 6 R$ & rs4601580 & $0.417,0.460$ & 0.4527 & $0.491,0.500$ & 0.8898 \\
\hline$I L 6 R$ & rs4553185 & $0.368,0.434$ & 0.2218 & $0.474,0.463$ & 0.8627 \\
\hline IL6R & rs4453032 & $0.273,0.320$ & 0.3479 & $0.431,0.449$ & 0.7804 \\
\hline$I L 6 R$ & rs4845374 & $0.116,0.121$ & 0.8845 & $0.103,0.096$ & 0.8352 \\
\hline$\| L 6 R$ & rs4240872 & $0.389,0.386$ & 0.9567 & $0.293,0.257$ & 0.5259 \\
\hline IL6R & rs4072391 & $0.343,0.361$ & 0.7265 & $0.216,0.184$ & 0.5295 \\
\hline IL6ST & rs10471960 & $0.080,0.104$ & 0.4582 & $0.129,0.125$ & 0.9184 \\
\hline IL6ST & rs10940495 & $0.259,0.303$ & 0.3717 & $0.267,0.239$ & 0.6055 \\
\hline IL6ST & rs11739048 & $0.089,0.105$ & 0.6247 & $0.155,0.140$ & 0.7295 \\
\hline IL6ST & rs6875155 & $0.071,0.103$ & 0.3233 & $0.121,0.125$ & 0.9173 \\
\hline IL10 & rs3024493 & $0.120,0.153$ & 0.3908 & $0.121,0.191$ & 0.1270 \\
\hline TNF & rs1799964 & $0.136,0.155$ & 0.6362 & $0.198,0.169$ & 0.5503 \\
\hline TNF & rs1800629 & $0.100,0.144$ & 0.2359 & $0.190,0.132$ & 0.2147 \\
\hline
\end{tabular}

${ }^{1}$ SNP accession numbers in dbSNP database (http://www.ncbi.nlm.nih.gov/SNP).

fluorescence units (FUs). Additionally, the association between cord blood proteins IL-6, TNF and gp130 and SNPs of the encoding genes was studied; including 100 infants with DNA sample available.

\section{Statistical analyses}

Case-control comparisons for the continuous and dichotomous clinical characteristics (GA, birth weight, intrauterine growth expressed as $Z$-score, intrauterine growth restriction $[\mathrm{IUGR}] \leq-2 \mathrm{SD}$, gender, and proportion of singletons) as well as the cord blood IL-6, TNF and soluble gp130 contents were performed by the nonparametric Mann-Whitney $U$-test and the Pearson $X^{2}$ test with SPSS Statistics 20.0 (IBM Corporation, Armonk, New York, USA). Differences in the cord blood IL-6, TNF and gp130 contents among the genotypes were analyzed with MannWhitney $U$-test and Kruskal-Wallis test. Haploview version 4.2 [27] was used for comparing case-control allele and haplotype frequencies ( $X^{2}$ tests), testing for HWE, and obtaining pairwise $L D$ values $\left(\mathrm{D}^{\prime}\right.$ and $\mathrm{r}^{2}$, where $\mathrm{D}^{\prime}$ refers to the strength of $\mathrm{LD}$ and $\mathrm{r}^{2}$ describes the correlation coefficient between the two loci; values close to 1 refer to strong LD or correlation between the two SNPs, respectively). PLINK 1.07 [28] was used for logistic regression analyses (to take the effect of potential risk factors into account together with the genetic factors).

Because some of the 44 SNPs included in the study were in LD with each other and thus not considered independent markers, SNPSpD [29], a method that takes LD between SNPs into account, was used to calculate the effective number of independent SNPs for each of the six genes. This resulted in a total of 32 independent SNPs; using the Bonferroni correction for multiple testing, a $P$ value of $<0.0016$ was considered significant.

Pairwise SNP-SNP interaction analyses were performed with the epistasis option in PLINK. The software uses logistic regression (for dichotomous phenotype) to provide an odds ratio (OR) for the interaction of each pair of SNPs by considering pairwise combinations of all of the SNPs. Redundant SNPs were excluded from the epistasis analysis based on the LD measurements (strong LD): only one SNP from each haploblock generated by Haploview was included (see Additional file 1). Additionally, SNPs were excluded if they showed significant deviation from HWE. With these exclusion criteria, 22 SNPs were included in the analysis, resulting in 231 pairwise SNP-SNP comparisons. 
Table 3 NR3C1 minor allele frequencies in cases and controls in the northern Finnish and Canadian populations

\begin{tabular}{|c|c|c|c|c|}
\hline \multirow[b]{2}{*}{ NR3C1 polymorphism ${ }^{1}$} & \multicolumn{2}{|l|}{ Northern Finland, $n=253$} & \multicolumn{2}{|l|}{ Canada, $n=126$} \\
\hline & Case, control minor allele frequency & $P$ value & Case, control minor allele frequency & $P$ value \\
\hline rs17287758 & $0.107,0.107$ & 0.9869 & $0.155,0.154$ & 0.9867 \\
\hline rs17209237 & $0.264,0.237$ & 0.5685 & $0.219,0.235$ & 0.7640 \\
\hline rs6196 & $0.200,0.184$ & 0.7034 & $0.198,0.184$ & 0.7709 \\
\hline rs10482689 & $0.107,0.105$ & 0.9381 & $0.155,0.154$ & 0.9867 \\
\hline rs10482682 & $0.339,0.319$ & 0.6811 & $0.327,0.347$ & 0.7529 \\
\hline rs6188 & $0.309,0.296$ & 0.7897 & $0.362,0.353$ & 0.8802 \\
\hline rs10482672 & $0.128,0.132$ & 0.9191 & $0.172,0.125$ & 0.2892 \\
\hline rs33383 & $0.460,0.500$ & 0.4799 & $0.482,0.441$ & 0.5248 \\
\hline rs2918417 & $0.304,0.293$ & 0.825 & $0.366,0.353$ & 0.8301 \\
\hline rs6877893 & $0.464,0.482$ & 0.7372 & $0.466,0.441$ & 0.6988 \\
\hline rs4912905 & $0.241,0.241$ & 0.9992 & $0.241,0.213$ & 0.5945 \\
\hline rs2918415 & $0.196,0.178$ & 0.6609 & $0.198,0.184$ & 0.7709 \\
\hline rs17399352 & $0.236,0.218$ & 0.6763 & $0.172,0.206$ & 0.5001 \\
\hline rs2963155 & $0.321,0.321$ & 0.9854 & $0.319,0.272$ & 0.4151 \\
\hline rs9324924 & $0.373,0.409$ & 0.4954 & $0.397,0.346$ & 0.4034 \\
\hline rs 7701443 & $0.366,0.359$ & 0.8903 & $0.353,0.353$ & 0.9933 \\
\hline rs4244032 & $0.134,0.153$ & 0.6201 & $0.190,0.169$ & 0.6714 \\
\hline rs4607376 & $0.500,0.495$ & 0.9247 & $0.500,0.449$ & 0.4146 \\
\hline rs13182800 & $0.116,0.147$ & 0.4074 & $0.190,0.169$ & 0.6714 \\
\hline rs12054797 & $0.255,0.320$ & 0.1888 & $0.302,0.294$ & 0.8953 \\
\hline rs4912910 & $0.382,0.414$ & 0.5472 & $0.353,0.360$ & 0.9100 \\
\hline rs12656106 & $0.446,0.407$ & 0.4619 & $0.431,0.508$ & 0.2274 \\
\hline rs12655166 & $0.268,0.324$ & 0.2641 & $0.302,0.294$ & 0.8953 \\
\hline
\end{tabular}

${ }^{1}$ SNP accession numbers in dbSNP database (http://www.ncbi.nlm.nih.gov/SNP).

The multiple testing-corrected significance threshold was $P<0.00022$.

\section{Genetic power of the study}

The power of the study was estimated by the Genetic Power Calculator [30] with an additive risk model (the allelic 1 degree of freedom test assuming a causal SNP with a MAF range of $0.1-0.5$ and a BPD prevalence of 0.2 ). Our population of very preterm infants, which included 114 cases and 265 controls (the combined northern Finnish and Canadian population) provided an estimate of $80 \%$ power (alpha $=0.05$ ) to detect genotypic relative risks of 1.56-1.7 for risk-allele carrier heterozygotes.

\section{Results}

Clinical characteristics of the BPD and control infants

Some of the clinical characteristics, such as GA, birth weight, and birth weight $Z$-score (birth weight adjusted for gestational age), differed significantly between infants with moderate-to-severe BPD and control infants with no-to-mild BPD (Table 1). There were no differences between cases and controls in the number of fetuses per pregnancy or in gender distribution (Table 1). Differences in the clinical characteristics were taken into account in the analyses when applicable.

\section{IL6, IL6R, IL6ST, IL10, TNF and NR3C1 polymorphisms and haplotypes in BPD cases and controls}

The allele frequency distribution of the 44 SNPs in BPD cases and controls was studied. None of the SNPs were associated with BPD in the northern Finnish or Canadian populations (Tables 2 and 3), nor did the clinical risk factors affect the results when included in the logistic regression analyses. When the northern Finnish and Canadian populations were combined, there were no significant associations with BPD (data not shown). There were no statistically significant haplotype associations with BPD in the genes studied when the two populations were analyzed separately or combined (data not shown).

Analysis of IL-6, TNF and gp130 proteins in cord blood Cord blood IL-6, TNF and gp130 were higher in very preterm infants who subsequently developed BPD ( $\mathrm{n}=35)$ than in those who did not develop BPD $(n=85)$ (median 
$1,299 \mathrm{FU}$ in cases vs. $1,054 \mathrm{FU}$ in controls, $P=0.34$; 514 FU in cases vs. $347 \mathrm{FU}$ in controls, $P=0.002$; $46,419 \mathrm{FU}$ in cases vs. $34,063 \mathrm{FU}$ in controls, $P<0.001$, respectively). Higher gp130 content predicted the risk of moderate-tosevere BPD as reported previously [15]. There were no statistically significant differences in the measures of cord blood IL-6, TNF or gp130 among the genotypes of the IL6, TNF or IL6ST SNPs, respectively. Small number of cases or individuals with the minor alleles of the SNPs may have limited the power for statistical significance.

\section{Study of epistasis (SNP-SNP interactions)}

Pairwise SNP-SNP interaction analyses were performed to identify epistasis between genes located in different genomic regions or chromosomes and to assess the interactions for associations with BPD susceptibility. A total of 231 valid SNP-SNP tests were performed with the 22 SNPs included in the analyses (corrected $P$ value threshold $<0.00022$ ). In the northern Finnish population, there was a SNP-SNP interaction that showed borderline significance for risk of moderate-to-severe BPD; this interaction was between IL6ST rs10471960 and IL10 rs3024493 SNPs $\left(P=0.0003, \mathrm{OR}_{\text {interaction }}=35.4\right.$; Table 4$)$. The homozygote carriers of major alleles of both SNPs (i.e., carrying both AA and GG genotypes of IL6ST rs10471960 and IL1O rs3024493, respectively) were at higher risk of BPD. Furthermore, the cases tended to have a higher combined major allele $(\mathrm{A}-\mathrm{G})$ frequency compared to controls ( $83.8 \%$ vs. $75.3 \%$, respectively). Thus, a combination of the major alleles could increase susceptibility to BPD or the minor alleles could be protective. This interaction between IL6ST rs10471960 and IL10 rs3024493 SNPs was not detected in the Canadian population $(P=0.65)$ or when the populations were combined $(P=0.020)$. In addition, no statistically significant interactions were detected in the Canadian population $(P>0.005)$ or in the combined northern Finnish and Canadian populations $(P>0.01)$.

\section{Replication study of IL6ST rs 10471960 and IL10 rs3024493 SNPs in BPD susceptibility}

Due to the suggestive signal in the epistasis analysis in the northern Finnish population, the IL6ST rs10471960 and IL10 rs3024493 SNPs were further analyzed in the replication population that included the additional Finnish and Hungarian populations. In the single marker association analysis, these two SNPs were not associated with BPD in the replication Finnish or Hungarian populations, or when the replication populations were combined with the initial populations. In the epistasis analyses, the interaction between the two SNPs was not significant in the replication Finnish $(P=0.30)$ or Hungarian $(P=0.61)$ populations, or when the initial northern Finnish and Canadian populations were combined with the replication populations $(P=0.13)$. The frequencies of the combined major alleles remained similar to those observed in the northern Finnish population $(83.8 \%$ in cases vs. $75.3 \%$ in controls), but the difference in the frequency between cases and controls was smaller in the sample set that included all of the studied populations $(76.1 \%$ in cases vs. $73.8 \%$ in controls).

\section{Discussion}

Despite the remarkable advances in perinatal care, BPD continues to be a major complication of prematurity. The increased survival of extremely preterm infants has contributed to an overall increase in the incidence of BPD with a long-term risk of respiratory dysfunction [1,2]. BPD occurs as the result of complex gene-environment interactions, but the etiology of BPD remains incompletely understood. Identification of the genetic component by family studies has highlighted the importance of genetic factors in predisposition to BPD [9]. Several polymorphisms have been associated with BPD in candidate gene and genome-wide association studies, but the associations have not been replicated at a statistically significant level $[8,10,11]$. However, considering the high $(\sim 80 \%)$ heritability of BPD, only a small part of this heritability can be explained by the potential susceptibility SNPs discovered thus far.

In the present case-control study, we investigated whether the IL6, IL6R, IL6ST, IL10, TNF, and NR3C1 genes were associated with susceptibility to BPD or whether the genes have effect on cord blood serum protein levels at the time of birth. These genes were selected based on their involvement in inflammatory responses and lung maturation. To our knowledge, no previous genetic studies of BPD have reported significant associations between any of

Table 4 Results of epistasis analysis in the northern Finnish population

\begin{tabular}{lllllll}
\hline Chr $\mathbf{1}$ & Gene 1 & SNP 1 & Chr 2 & Gene 2 & SNP 2 & P value of interaction* \\
\hline 1 & IL10 & rs3024493 & 5 & IL6ST & rs10471960 & 0.0003 \\
1 & IL6R & rs1386821 & 7 & IL6 & rs2069832 & 0.0025 \\
5 & NR3Cl & rs17209237 & 6 & TNF & rs1800629 & 0.0049 \\
1 & IL10 & rs3024493 & 5 & NR3C1 & rs17209237 & 0.0063 \\
\hline
\end{tabular}

${ }^{*}$ None of the interactions were significant after correcting for multiple comparisons $(P<0.0002$ as threshold for significance). Only SNP $\times$ SNP interactions with $P$ values $<0.01$ are shown. 
these genes and moderate-to-severe BPD. Previous studies of TNF polymorphisms yielded inconsistent results or associations that have not been replicated in subsequent studies [31-33]. In addition to single-SNP analyses, we investigated whether there is evidence for epistasis between these genes in predisposition to BPD. None of the 44 polymorphisms that we studied showed significant associations with BPD in the single marker case-control analyses. There were no significant associations between cord blood IL-6, TNF and gp130 and polymorphisms of the encoding genes. In the epistasis study, a suggestive interaction between IL6ST rs10471960 and IL10 rs3024493 SNPs was observed in the population that originated in the northern Finland $(P=0.0003)$. This interaction did not remain significant for predisposition to moderate-to-severe BPD after correction for multiple comparisons, and the detected interaction was not replicated in the additional studied populations.

Epistasis may be one of the factors that account for the missing heritability in complex diseases [34]. However, assessing whether the detected interactions in epistasis analyses represent true gene-gene interactions is not a straightforward task. To our knowledge, interactions between IL6ST and IL10 have not been reported previously. IL-6 levels and actions, namely, IL-6 signaling, are dependent on the two receptors IL-6R and gp130. gp130, encoded by IL6ST, is a common receptor subunit that is shared with other receptors belonging to the IL- 6 cytokine family. Different pathways of IL-6 signaling represent different types of cells that respond to IL-6; this could explain both the pro- and anti-inflammatory actions of IL-6 cytokine [35,36]. In infants that subsequently developed BPD, increased concentrations of IL- 6 and soluble forms of IL-6R and gp130 were observed with different ratios in tracheal aspirate suggesting that altered IL-6 signaling may have a role in pulmonary inflammation [37]. Additionally, high cord blood levels of soluble gp130 at birth have been shown to predict subsequent development of BPD among very preterm infants [15], and the role of IL-10 in BPD has been investigated [13,38]. Thus, the potential interaction we observed in this study may be biologically relevant, but it requires further investigation.

The strengths of our study are the use of genetically relatively homogenous Finnish populations, the availability of multiple populations of European descent (i.e. we did not include individuals of clearly different ethnicities to avoid bias arising from population structure), and the strict phenotypic criteria among the participating centers. We analyzed common polymorphisms of several genes with potentially relevant roles in the pathogenesis of BPD. Possible limitations of this study are that the initial study population (northern Finnish) was relatively small and that the suggestive interaction was not observed in the other populations. Our northern Finnish population is likely more genetically homogenous than populations that originated in other parts of Finland [39] and compared to other populations of European origin [40]. This could have affected the different patterns of interaction between SNPs that we observed among the different populations in this study. An additional replication study is needed, with a larger population.

\section{Conclusions}

None of the polymorphisms within the IL6, IL6R, IL6ST, IL10, TNF, and NR3C1 genes were associated with BPD susceptibility, nor were they associated with the measured biomarkers. We observed a modest evidence of epistasis, i.e., a potential SNP-SNP interaction that could be associated with the risk of BPD. To our knowledge, epistasis has not been previously addressed in genetic studies of $\mathrm{BPD}$. We propose that further studies of gene-gene interactions in the etiology of BPD are needed.

\section{Additional file}

Additional file 1: Additional data for "A study of genes encoding cytokines (IL6, IL10, TNF), cytokine receptors (IL6R, IL6ST), and glucocorticoid receptor (NR3C1) and susceptibility to bronchopulmonary dysplasia" by Huusko JM, Karjalainen MK, Mahlman M, Haataja R, Kari MA, Andersson S, Toldi G, Tammela O, Rämet M, Lavoie PM, and Hallman M.

\section{Abbreviations}

BPD: Bronchopulmonary dysplasia; FU: Fluorescence unit; GA: Gestational age; HWE: Hardy-Weinberg equilibrium; IUGR: Intrauterine growth restriction; LD: Linkage disequilibrium; MAF: Minor allele frequency; OR: Odds ratio; PMA: Postmenstrual age; SNP: Single nucleotide polymorphism; tSNP: Tagging SNP.

\section{Competing interests}

The authors declare that they have no competing interests.

\section{Authors' contributions}

JMH designed and performed experiments, analyzed the data, and drafted the initial manuscript. MKK supervised and contributed to the data analysis, critically reviewed and revised the manuscript. MM, RH, MAK, SA, GT and OT contributed to obtaining patient data and/or DNA, reviewed and revised the manuscript. MR and PML contributed to obtaining patient data and DNA, critically reviewed and revised the manuscript. $\mathrm{MH}$ designed and supervised the study, critically reviewed and revised the manuscript. All authors have approved the final manuscript as submitted.

\section{Acknowledgements}

We would like to thank Maarit Haarala for laboratory assistance; Tuula Kaukola and Stephen Kingsmore for generating the biomarker data; Riitta Vikeväinen, Leena Kivinen, Marita Suni, Satu Ekblad, Sirpa Toivonen, Anneli Paloranta, Jaana Vuollet-Puurunen, and Pia Pohjola for sample and data collection; Leena Haataja and Helena Lapinleimu for subject enrollment and sample collection; Risto Bloigu for statistical consulting; and Kira Heller for language editing of the manuscript. Mihoko Ladd and Barb Kamstra are acknowledged for coordinating sample collection and enrolment in Vancouver and Edmonton (Canada), respectively. Miklós Szabó and Tivadar Tulassay are acknowledged for sample and data collection in Hungary. Genotyping of the SNP markers was performed by the Technology Centre, Institute for Molecular Medicine Finland (FIMM), University of Helsinki. 


\section{Funding}

This work was supported by the Alma and K. A. Snellman Foundation, Oulu, Finland (JMH, MKK), the Emil Aaltonen Foundation (JMH, MKK), the Foundation of Pediatric Research in Finland (MKK, RH), the Academy of Finland (grant number 126662, MH), the Sigrid Juselius Foundation (MH), and Competitive Research Funding of the Tampere University Hospital (MR). PML is supported by Michael Smith Foundation for Health Research Career Investigator and Child \& Family Research Institute Clinician-Scientist Awards. The Canadian recruitment portion of this study was funded by a British Columbia Lung Association Grant (PML).

\section{The Gen-BPD Study Group}

The Gen-BPD Study Group includes the following investigators from the following University Hospital Centers of Finland: Children's Hospital, Helsinki University Central Hospital and University of Helsinki: Sture Andersson, MD, PhD; Cecilia Janér, MD; M. Anneli Kari, MD, PhD; and Ilkka Ketola, MD, PhD. Department of Pediatrics, Kuopio University Hospital, Kuopio, Finland: Ulla Sankilampi, MD, PhD. Department of Pediatrics, Institute of Clinical Medicine, University of Oulu and Department of Children and Adolescents, Oulu University Hospital, Oulu, Finland: Mikko Hallman, MD, PhD; Johanna M. Huusko, PhD; Minna K. Karjalainen, PhD; Mari Mahlman, MD; and Riitta Marttila, MD, PhD. Department of Pediatrics, Tampere University Hospital, Tampere, Finland: Mika Rämet, MD, PhD and Outi Tammela, MD, PhD. Department of Pediatrics, Turku University Hospital, Turku, Finland: Liisa Lehtonen, MD, PhD. And investigator Thierry Lacaze-Masmonteil, MD, PhD from the Children's Hospital of Eastern Ontario, University of Ottawa, Ottawa, Ontario, Canada.

\section{Author details}

'Department of Pediatrics, Institute of Clinical Medicine, Medical Research Center Oulu, Oulu University Hospital and University of Oulu, Oulu, Finland. ${ }^{2}$ Department of Children and Adolescents, Oulu University Hospital, Oulu, Finland. ${ }^{3}$ Biocenter Oulu, Oulu, Finland. ${ }^{4}$ Children's Hospital, Helsinki University Central Hospital and University of Helsinki, Helsinki, Finland. ${ }^{5}$ First Department of Pediatrics, Semmelweis University, Budapest, Hungary. ${ }^{6}$ Department of Pediatrics, Tampere University Hospital, Tampere, Finland. ${ }^{7}$ BioMediTech, University of Tampere, Tampere, Finland. ${ }^{8}$ Child and Family Research Institute of British Columbia, Vancouver, Canada.

Received: 24 June 2014 Accepted: 13 October 2014

Published online: 01 November 2014

\section{References}

1. Bhandari A, McGrath-Morrow S: Long-term pulmonary outcomes of patients with bronchopulmonary dysplasia. Semin Perinatol 2013, 37:132-137.

2. Fanaroff $A A$, Stoll BJ, Wright $L L$, Carlo WA, Ehrenkranz RA, Stark $A R$, Bauer $C R$, Donovan EF, Korones SB, Laptook AR, Lemons JA, Oh W, Papile LA, Shankaran S, Stevenson DK, Tyson JE, Poole WK, NICHD Neonatal Research Network: Trends in neonatal morbidity and mortality for very low birthweight infants. Am J Obstet Gynecol 2007, 196:147.e1-147.e8.

3. Bose C, Van Marter LJ, Laughon M, O'Shea TM, Allred EN, Karna P, Ehrenkranz RA, Boggess K, Leviton A, Extremely Low Gestational Age Newborn Study Investigators: Fetal growth restriction and chronic lung disease among infants born before the 28th week of gestation. Pediatrics 2009, 124:e450-e458.

4. Speer CP: Inflammation and bronchopulmonary dysplasia: a continuing story. Semin Fetal Neonatal Med 2006, 11:354-362.

5. Bhandari V, Bizzarro MJ, Shetty A, Zhong X, Page GP, Zhang H, Ment LR, Gruen JR, Neonatal Genetics Study Group: Familial and genetic susceptibility to major neonatal morbidities in preterm twins. Pediatrics 2006, 117:1901-1906.

6. Lavoie PM, Pham C, Jang KL: Heritability of bronchopulmonary dysplasia, defined according to the consensus statement of the national institutes of health. Pediatrics 2008, 122:479-485.

7. Parker RA, Lindstrom DP, Cotton RB: Evidence from twin study implies possible genetic susceptibility to bronchopulmonary dysplasia. Semin Perinatol 1996, 20:206-209.

8. Hadchouel A, Durrmeyer X, Bouzigon E, Incitti R, Huusko J, Jarreau PH, Lenclen R, Demenais F, Franco-Montoya ML, Layouni I, Patkai J, Bourbon J, Hallman M, Danan C, Delacourt C: Identification of SPOCK2 as a susceptibility gene for bronchopulmonary dysplasia. Am J Respir Crit Care Med 2011, 184:1164-1170.

9. Lavoie PM, Dube MP: Genetics of bronchopulmonary dysplasia in the age of genomics. Curr Opin Pediatr 2010, 22:134-138.

10. Shaw GM, O'Brodovich HM: Progress in understanding the genetics of bronchopulmonary dysplasia. Semin Perinatol 2013, 37:85-93.

11. Wang H, St Julien KR, Stevenson DK, Hoffmann TJ, Witte JS, Lazzeroni LC, Krasnow MA, Quaintance CC, Oehlert JW, Jelliffe-Pawlowski LL, Gould JB, Shaw GM, O'Brodovich HM: A Genome-Wide Association Study (GWAS) for Bronchopulmonary Dysplasia. Pediatrics 2013, 132:290-297.

12. Coalson JJ: Pathology of bronchopulmonary dysplasia. Semin Perinatol 2006, 30:179-184.

13. Bose $\mathrm{CL}$, Dammann CE, Laughon MM: Bronchopulmonary dysplasia and inflammatory biomarkers in the premature neonate. Arch Dis Child Fetal Neonatal Ed 2008, 93:F455-F461.

14. Ambalavanan N, Carlo WA, D'Angio CT, McDonald SA, Das A, Schendel D, Thorsen P, Higgins RD, Eunice Kennedy Shriver National Institute of Child Health and Human Development Neonatal Research Network: Cytokines associated with bronchopulmonary dysplasia or death in extremely low birth weight infants. Pediatrics 2009, 123:1132-1141.

15. Kaukola T, Tuimala J, Herva R, Kingsmore S, Hallman M: Cord immunoproteins as predictors of respiratory outcome in preterm infants. Am J Obstet Gynecol 2009, 200:100.e1-100.e8.

16. Yoon BH, Romero R, Jun JK, Park KH, Park JD, Ghezzi F, Kim Bl: Amniotic fluid cytokines (interleukin-6, tumor necrosis factor-alpha, interleukin-1 beta, and interleukin-8) and the risk for the development of bronchopulmonary dysplasia. Am J Obstet Gynecol 1997, 177:825-830.

17. McGowan EC, Kostadinov S, McLean K, Gotsch F, Venturini D, Romero R, Laptook AR, Sharma S: Placental IL-10 dysregulation and association with bronchopulmonary dysplasia risk. Pediatr Res 2009, 66:455-460.

18. Nicolaides NC, Galata Z, Kino T, Chrousos GP, Charmandari E: The human glucocorticoid receptor: molecular basis of biologic function. Steroids 2010, 75:1-12

19. Yang N, Ray DW, Matthews LC: Current concepts in glucocorticoid resistance. Steroids 2012, 77:1041-1049.

20. Jobe $\mathrm{AH}$, Bancalari E: Bronchopulmonary dysplasia. Am J Respir Crit Care Med 2001, 163:1723-1729.

21. Walsh MC, Yao Q, Gettner P, Hale E, Collins M, Hensman A, Everette R, Peters N, Miller N, Muran G, Auten K, Newman N, Rowan G, Grisby C, Arnell K, Miller L, Ball B, McDavid G, National Institute of Child Health and Human Development Neonatal Research Network: Impact of a physiologic definition on bronchopulmonary dysplasia rates. Pediatrics 2004, 114:1305-1311.

22. Lavoie PM, Ladd M, Hirschfeld AF, Huusko J, Mahlman M, Speert DP, Hallman M, Lacaze-Masmonteil T, Turvey SE: Influence of common nonsynonymous Toll-like receptor 4 polymorphisms on bronchopulmonary dysplasia and prematurity in human infants. PLoS One 2012, 7:e31351.

23. Karjalainen MK, Huusko JM, Ulvila J, Sotkasiira J, Luukkonen A, Teramo K, Plunkett J, Anttila V, Palotie A, Haataja R, Muglia LJ, Hallman M: A potential novel spontaneous preterm birth gene, $A R$, identified by linkage and association analysis of X chromosomal markers. PLoS One 2012, 7:e51378.

24. Hannelius U, Lindgren CM, Melen E, Malmberg A, von Dobeln U, Kere J: Phenylketonuria screening registry as a resource for population genetic studies. J Med Genet 2005, 42:e60.

25. The International HapMap Project [www.hapmap.org]

26. Schweitzer B, Roberts S, Grimwade B, Shao W, Wang M, Fu Q, Shu Q, Laroche I, Zhou Z, Tchernev VT, Christiansen J, Velleca M, Kingsmore SF: Multiplexed protein profiling on microarrays by rolling-circle amplification. Nat Biotechnol 2002, 20:359-365.

27. Barrett JC, Fry B, Maller J, Daly MJ: Haploview: analysis and visualization of LD and haplotype maps. Bioinformatics 2005, 21:263-265.

28. Purcell S, Neale B, Todd-Brown K, Thomas L, Ferreira MA, Bender D, Maller J, Sklar P, de Bakker PI, Daly MJ, Sham PC: PLINK: a tool set for wholegenome association and population-based linkage analyses. Am J Hum Genet 2007, 81:559-575.

29. Nyholt DR: A simple correction for multiple testing for single-nucleotide polymorphisms in linkage disequilibrium with each other. Am J Hum Genet 2004, 74:765-769.

30. Genetic Power Calculator [http://pngu.mgh.harvard.edu/ purcell/gpc/]

31. Chauhan M, Bombell S, McGuire W: Tumour necrosis factor (--308A) polymorphism in very preterm infants with bronchopulmonary 
dysplasia: a meta-analysis. Arch Dis Child Fetal Neonatal Ed 2009, 94:F257-F259

32. Kazzi SN, Kim UO, Quasney MW, Buhimschi I: Polymorphism of tumor necrosis factor-alpha and risk and severity of bronchopulmonary dysplasia among very low birth weight infants. Pediatrics 2004, 114:e243-e248.

33. Strassberg SS, Cristea IA, Qian D, Parton LA: Single nucleotide polymorphisms of tumor necrosis factor-alpha and the susceptibility to bronchopulmonary dysplasia. Pediatr Pulmonol 2007, 42:29-36.

34. Manolio TA, Collins FS, Cox NJ, Goldstein DB, Hindorff LA, Hunter DJ, McCarthy MI, Ramos EM, Cardon LR, Chakravarti A, Cho JH, Guttmacher AE, Kong A, Kruglyak L, Mardis E, Rotimi CN, Slatkin M, Valle D, Whittemore AS, Boehnke M, Clark AG, Eichler EE, Gibson G, Haines JL, Mackay TF, McCarroll SA, Visscher PM: Finding the missing heritability of complex diseases. Nature 2009, 461:747-753.

35. Heinrich PC, Behrmann I, Haan S, Hermanns HM, Muller-Newen G, Schaper F: Principles of interleukin (IL)-6-type cytokine signalling and its regulation. Biochem J 2003, 374:1-20.

36. Rose-John S: IL-6 trans-signaling via the soluble IL-6 receptor: importance for the pro-inflammatory activities of IL-6. Int J Biol Sci 2012, 8:1237-1247.

37. von Bismarck P, Claass A, Schickor C, Krause MF, Rose-John S: Altered pulmonary interleukin- 6 signaling in preterm infants developing bronchopulmonary dysplasia. Exp Lung Res 2008, 34:694-706.

38. Paananen R, Husa AK, Vuolteenaho R, Herva R, Kaukola T, Hallman M: Blood cytokines during the perinatal period in very preterm infants: relationship of inflammatory response and bronchopulmonary dysplasia. J Pediatr 2009, 154:39-43.e3.

39. Jakkula E, Rehnstrom K, Varilo T, Pietilainen OP, Paunio T, Pedersen NL, de Faire U, Jarvelin MR, Saharinen J, Freimer N, Ripatti S, Purcell S, Collins A, Daly MJ, Palotie A, Peltonen L: The genome-wide patterns of variation expose significant substructure in a founder population. Am J Hum Genet 2008, 83:787-794.

40. Sajantila A, Salem AH, Savolainen P, Bauer K, Gierig C, Paabo S: Paternal and maternal DNA lineages reveal a bottleneck in the founding of the Finnish population. Proc Natl Acad Sci U S A 1996, 93:12035-12039.

doi:10.1186/s12881-014-0120-7

Cite this article as: Huusko et al: A study of genes encoding cytokines (IL6, IL10, TNF), cytokine receptors (IL6R, IL6ST), and glucocorticoid receptor (NR3C1) and susceptibility to bronchopulmonary dysplasia. BMC Medical Genetics 2014 15:120.

\section{Submit your next manuscript to BioMed Central and take full advantage of:}

- Convenient online submission

- Thorough peer review

- No space constraints or color figure charges

- Immediate publication on acceptance

- Inclusion in PubMed, CAS, Scopus and Google Scholar

- Research which is freely available for redistribution 